\title{
Livros de matemática na América Espanhola, durante o século XIX ${ }^{1}$
}

\author{
Mathematics books in Spanish America during the XIXth century.
}

João Bosco Pitombeira Fernandes de Carvalho ${ }^{2,3}$

\begin{abstract}
Resumo
Abordaremos os livros de matemática usados no século XIX, em alguns dos países latino-americanos de colonização espanhola, em vários níveis da escolaridade, visando a despertar o interesse por uma rica área de pesquisa. Mostraremos o papel importante desempenhado por Benito Bails e José Mariano Vallejo e a contribuição independente, praticamente desconhecida, de Indalécio Liévano para a fundamentação dos números reais. O desenvolvimento do trabalho deixa claro, esperamos, as diferenças entre a produção de livros de matemática na América de colonização espanhola e a de colonização portuguesa.
\end{abstract}

Palavras-chave: Benito Bails; José Mariano Vallejo; Indalécio Lievano; História dos livros texto de matemática; História da educação matemática na América Latina.

\begin{abstract}
We look at mathematics textbooks used, during the XIX century, in some Latin American countries colonized by Spain. These books were addressed to different periods of school life, but mainly in secondary schools. We stress the importance of Benito Bails and José Mariano Vallejo and Indalécio Lievano's independent contribution, practically unknown, to the foundations of the real number system. This work makes clear, we hope, the differences between mathematics books production in Spanish America and Portuguese America (Brazil).
\end{abstract}

Keywords: Benito Bails; José Mariano Vallejo; Indalécio Lievano; History of Mathematics textbooks; History of mathematics education in Latin America.

\section{Introdução}

Como bem dito por Valente (2008), o livro didático e a educação matemática têm histórias inseparáveis, pois ele é essencial "para investigar o trajeto histórico da educação matemática”. Referindo-se especificamente ao Brasil, mas descrevendo uma situação que pode ser generalizada para toda a América Latina, no século XIX, quando os sistemas educacionais dos vários países foram instituídos, Flávia Soares assinala que os "[1]ivros texto são importantes, pois estruturam as disciplinas escolares, e são fundamentais na criação e

\footnotetext{
${ }^{1}$ Este trabalho é uma ampliação e reformulação completa de parte de Carvalho (2014).

2 Doutor em Matemática pela University of Chicago. Professor Visitante do Programa de Pós-Graduaçao em Educaçao Matematica da Universidade Federal do Mato Gorsso do Sul, Brasil. Email: jbpfcarvalho@gmail.com.

${ }^{3}$ Como professor visitante, agradeço a acolhida carinhosa e produtiva dos colegas e alunos do Programa de Pós-Graduação em Educação Matemática da Universidade Federal do Mato Grosso do Sul. O autor deseja agradecer também aos revisores pelas sugestões que muito contribuíram para melhorar este trabalho.
} 
DOI: http://dx.doi.org/ 10.20396/zet.v25i2.8647053

institucionalização da escola (...)" (Soares, 2011, p. 1).

Assim, a análise histórica de livros de matemática é importante na história da educação matemática, e é necessariamente precedida por levantamentos dos mesmos, seguindo critérios temáticos, cronológicos ou geográficos, entre outros. Neste trabalho, examinamos livros de matemática usados ou publicados na América de língua espanhola (chamada, de agora em diante, simplesmente América Espanhola), utilizados em todos os níveis de escolaridade, como primeira etapa para analisá-los historicamente. Tentaremos, aqui, fazer um esboço da situação, de maneira confessadamente incompleta, a fim de familiarizar os leitores brasileiros com alguns dos autores e títulos mais difundidos na América Espanhola no século XIX, para os ensinos elementar, secundário e posterior). Além disso, há algumas referências à situação no Brasil, embora isso seja secundário em relação aos objetivos deste trabalho.

\section{Preliminares e antecedentes}

Em primeiro lugar, é necessário chamar atenção para uma diferença entre a América Espanhola e a América de língua portuguesa: Enquanto que na última, até 1808, era rigorosamente proibida a impressão de livros, na primeira, observamos, bem cedo, a existência de casas impressoras. Até 1638, todos os livros de matemática publicados no Novo Mundo o foram na América Espanhola, num total de 15 títulos. Em verdade, Burdick (2009) lista 19 livros, mas em seu levantamento estão incluídas obras de filosofia que usam exemplos de matemática. Se acatássemos seu critério, deveríamos aceitar como tratados de matemática da Grécia Antiga algumas obras de Platão e de Aristóteles. Assim, preferimos acompanhar David Eugene Smith (1921) e considerar que o primeiro livro de matemática impresso nas três Américas data de 1556, o Sumário compendioso, de Juan Diez, publicado na cidade do México, no então Vice Reinado da Nova Espanha. ${ }^{4}$ Contrastando com isso, as primeiras obras de matemática escritas no Brasil datam, respectivamente, de 1744 e 1748, 188 anos depois, respectivamente o Exame de artilheiros e o Exame de bombeiros, de José Fernandes Pinto Alpoim, embora seja controvertido o local em que foram realmente impressas, Lisboa ou Madrid (Hallewell, 2005, pp. 92-93). ${ }^{5}$

Pode-se afirmar, com segurança, que houve, durante o século XIX, mais livros impressos na América Espanhola do que no Brasil (Hallewell, 1982, 2005; Garcia, 1998; Alcaráz, 2007), embora a partir de 1808 tenha havido um grande esforço, no Brasil, para traduzir livros de matemática e de ciências, necessários nos cursos das escolas profissionais

\footnotetext{
${ }^{4}$ Pouco se sabe sobre Juan Diez, e existem controvérsias sobre sua exata situação eclesiástica (Burdick, 2009, pp. 39-40).

${ }^{5}$ Embora os governantes portugueses proibissem a existência de casas impressoras no Brasil e exercessem censura sobre livros importados, eles eram contrabandeados e há notícias de casas impressoras antes de 1808 , ano em que as Cortes de Lisboa se transferiram para o Brasil e foi criada a Impressão Régia, por D. João VI, no Rio de Janeiro (Frieiro, 1957; Hallewell, 1982; 2005; Silva, 1981).
} 
DOI: http://dx.doi.org/ 10.20396/zet.v25i2.8647053

que tinham acabado de ser fundadas, entre eles os Éléments de Géométrie de Legendre, publicados em 1809, a Géométrie descriptive de Monge, em 1812, e o tratado de Euler Vollständige Anleitung zur Algebra, também em 1809 (Silva, 2009). Foram, além disso, traduzidos cinco livros de Lacroix.

Em toda a América Latina, as escolas profissionais, tanto militares quanto civis, foram importantes para a divulgação da matemática. Muitas das obras escritas no continente ou traduzidas para o espanhol ou português destinavam-se a essas escolas. Embora o discurso inicial da independência das colônias espanholas ressaltasse a importância da educação para todos, a necessidade premente de formar profissionais para a administração e defesa dos novos países, juntamente com a importância de não alienar as classes abastadas, fez com que rapidamente a ênfase fosse o estabelecimento de instituições de ensino que preparassem militares, advogados, médicos e engenheiros, todos urgentemente necessários.

A fim de dar uma ideia da matemática que uma pessoa culta lia na América Espanhola, mencionamos que a biblioteca pessoal de Francisco de Saavedra, o segundo governador de Caracas, e que morreu em 1819, continha exemplares de três obras de Benito Bails - Principios de matemática (Madrid, 1789), Elementos de matemática (Madrid, 1793) e Aritmética para negociantes (Madrid, 1790) - além de um exemplar do Tratado de matemáticas de José Radón, publicado em Madrid, no ano de 1794 (Martínez, s.d.).

\section{Benito Bails e José Mariano Vallejo}

$\mathrm{Na}$ América colonizada pelos espanhóis, a língua e a herança cultural comum permitiram que algumas obras de autores espanhóis, publicados na Espanha ou no Novo Mundo, fossem usadas em mais de uma colônia espanhola ou, mais tarde, em mais de um país, como se pode verificar para o caso de alguns dos livros mencionados neste trabalho, e também comparando-o com Beyer (2015). Entre os livros de uso corrente mais influentes temos os Princípios de matemáticas (primeira edição em 1776) de Benito Bails, com 3 volumes, e seu Elementos de matemáticas, em 10 volumes, publicados entre 1772 e 1783. Além desses, foram influentes, em vários países daquela parte do continente, o Compendio de matemáticas puras y mixtas de José Mariano Vallejo, publicado em 1819, e seu Tratado Elemental de Matemáticas publicado de 1812 a 1817. Comentaremos brevemente esses autores e suas obras, antes de fazermos uma apresentação de vários textos utilizados especificamente em alguns dos países que se tornaram independentes da Espanha. Evidentemente, não é possível, em um só trabalho, abordar os livros de matemática utilizados em toda a América espanhola. Selecionamos alguns países que apresentam diferentes características históricas e culturais representativas do conjunto: México, por ter sido a sede do Vice Reinado da Nova Espanha, com o qual se iniciou a colonização espanhola no continente; Colômbia, a sede do Vice Reinado de Nova Granada; Venezuela, parte, com outros países recém-independentes, da Grã Colômbia; Chile e Costa Rica por serem, no século XIX, países periféricos na América Latina Espanhola. 
DOI: http://dx.doi.org/ 10.20396/zet.v25i2.8647053

Benito Bails (Barcelona, 1730 - Madrid, 1797) foi importante matemático espanhol do século XVIII. Sua família mudou-se, quando ele ainda era criança, para Perpignan, na França. Estudou, com destaque, nas universidades de Perpignan e de Toulouse. Em 1754 mudou-se para Paris, onde conviveu com Condorcet, D'Alembert e outros intelectuais. Em 1763 regressa à Espanha, quando foi escolhido professor de matemática da recém-fundada Real Academia de Bellas Artes de San Fernando (1752), em Madrid, em que lecionou até seu falecimento. A academia se dedicava ao ensino da pintura, escultura e arquitetura, e nela Bails foi o diretor de matemáticas. Embora não seja uma obra com contribuições originais de Bails, seus extensos Elementos de Matemática, publicados de 1772 a 1783 e reimpressos várias vezes foram importantes por mostrarem à Espanha a matemática mais moderna que se conhecia na Europa da época. ${ }^{6}$ Esta obra inclui a arquitetura e a física como partes da matemática, possivelmente para permitir sua utilização em cursos diferentes. Os volumes desta obra enciclopédica estão divididos como segue: 1- Geometria e trigonometria; 2 álgebra; 3 - as cônicas, o cálculo infinitesimal e as equações diferenciais; 4, 5, 6 - dinâmica, hidrodinâmica e ótica; 7, 8 - astronomia de posição; 9 - arquitetura; 10 - os logaritmos. Todos os volumes contêm prefácios, em que Bails discorre sobre as obras consultadas ou transcritas.

A obra não tem pretensão de originalidade, seu objetivo é expor, didaticamente, de maneira atualizada, partes da matemática, da física e da astronomia. No prefácio do primeiro volume, Bails escreve:

Enterados más de lo que quisiéramos de que eran muy extrañas para nuestros hombres las doctrinas que íbamos a publicar, y de lo mucho que importaba saliese al público con toda posible brevedad nuestro trabajo, nos detuvimos poco en dar a las materias, que nos tocaban tratar, un aspecto muy diferente del que tenían en las obras clásicas que nos dedicamos a extractar o copiar; sólo pusimos cuidado en echar mano de las más celebradas, y enlazar con todo esmero los pedazos que para la formación de un tratado sacábamos de diferentes [...] pero nos pareció después, que quatro tomos de Matemática pura, podría dar visos de fundadas a las quejas de algunos hombres que miraban con no poca oposición nuestro destino, los quales, ciñendo su patriotismo al corto número de los objetos que alcanza, o tiene alrededor de sí, coadyuvan con repugnancia, o dexan de oponerse violentos a las empresas de universal utilidad. Y hechos cargo de que, todo bien considerado, los tratados mixtos son los que más importan, sacrificamos la especulativa a la práctica... (Elementos de Matemática, I, pp. XIII- XIV).

Palacio (1983, p. 68) tem uma visão bem crítica dos compêndios de Bails, que ele considera como simples, embora competentes, traduções. Segundo ele, as partes de aritmética e álgebra dos Elementos de Matemática são cópias de Bézout, a análise matemática é devida a l'Hôpital, e o cálculo das variações é copiado de Lagrange. Por outro lado, Garma (1973, p. 62) chama atenção que:

Este criterio por el que cada nuevo texto que se escribía reproducía de forma igual que los anteriores la materia de la geometria o del álgebra se usó en toda Europa durante el siglo XVIII. No hay más que comparar los libros de texto franceses entre sí para

\footnotetext{
${ }^{6}$ Ver www.mcnbiografias.com, consultado em 9 de junho de 2014.
} 
DOI: http://dx.doi.org/ 10.20396/zet.v25i2.8647053

descubrir que, salvo las obras más importantes por sus aportaciones nuevas, las demás sólo variaban en la disposición de los temas.

Ao contrário de Bails, a formação de José Mariano Vallejo y Ortega (1779 - 1846) deu-se totalmente na Espanha. Engenheiro, matemático e educador, foi aluno da Faculdade de Filosofia e Artes da Universidade de Granada e, posteriormente, da Real Academia de Belas Artes de San Fernando, em Madrid. Em 1802, foi nomeado catedrático de matemática, fortificação, ataque e defesa de praças no Real Seminário de Nobles, de Madrid. ${ }^{7}$ Entre suas inúmeras obras citamos: Aritmética de niños (1804); Adiciones a la Geometría de don Benito Bails (1806); Ideas primarias que deben darse a los niños acerca de los números (1806);Tratado elemental de matemáticas (1812 -1813, 1817); Compendio de Matemáticas puras y mistas (1819-1840); Geometria de niños (1845). Postumamente, foram publicados seu Tratado completo de Matemáticas (1856) e sua Álgebra (1856), ambos na França. O Tratado elemental de matemáticas é uma obra enciclopédica que, embora menor do que os Elementos de matemática de Bails, é mais atualizada. A Universidade de Salamanca e a Coroa Espanhola recomendaram que os Elementos fossem reimpressos, sem aumento de custos, na América espanhola, na qual a Aritmética de niños foi muito utilizada. Data de 1807 seu trabalho mais avançado de matemática, a Memoria sobre la curvatura de las lineas en sus diferentes puntos, sobre el radio de curvatura, y sobre las evolutas, en que se expone esta teoría por los dos métodos, analítico y sintético, independientemente el uno del otro, publicado em Madrid, 1807. No Tratado elemental de matemáticas (5 volumes), Vallejo estuda aritmética, álgebra, geometria, seções cônicas, trigonometria retilínea e esférica, aplicações da álgebra à geometria, teoria geral das equações, funções, séries, cálculo das diferenças, cálculo diferencial e integral, mecânica dos sólidos e fluidos. Como parte de suas preocupações educacionais, fundou e dirigiu duas escolas normais em Madrid. São muitas suas publicações voltadas para o ensino primário, não só de matemática. ${ }^{8}$

Apresentaremos agora livros adotados em alguns países da América Espanhola, escolhidos por representarem, no século XIX, distintas realidades histórico-culturais deste vasto subcontinente. ${ }^{9}$

\footnotetext{
${ }^{7}$ Para o papel desempenhado pelo Real Seminario ver (Soubeyroux, 1995). Sobre Vallejo, ver também (Gentil Baldrich, 1999) e (Perez \& Sánchez, 1990).

${ }^{8}$ Ver www.mcnbiografias.com, consultado em 13 de junho de 2014. Ver também (Perez e Sanchez 1990).

9 Alterações no mapa político da América Espanhola no século XIX, que marca a independência das antigas colônias espanholas, tornam, por vezes, complicado referir-se a certos países. Por exemplo, após sua independência da Espanha, o Vicereinado de Nova Granada, com sede em Bogotá, tornou-se (com pequenas diferenças), a Grã Colômbia (1819-1831), que incluía vários países do norte da América do Sul, como o Equador e a Venezuela, e do sul da América Central, como Costa Rica e Panamá. Como regra geral, chamaremos de venezuelanos acontecimentos na Venezuela atual, mesmo se tenham ocorrido quando a Venezuela era parte da Grã Colômbia.
} 


\section{México}

DOI: http://dx.doi.org/ 10.20396/zet.v25i2.8647053

No México, os livros texto usados tanto no Real Seminario de Minas (fundado em 1792) e na Real Academia de San Carlos (criada em 1781) foram, inicialmente, os Principios de matemáticas de Benito Bails e, posteriormente e menos influente, o Compendio de matemáticas puras y mixtas (1819-1840) do engenheiro e matemático espanhol José Mariano Vallejo y Ortega (1779 - 1846) (Garcia, 1998, p. 32). Esta obra, fortemente influenciada pelas ideias modernas de Cauchy sobre a análise matemática é cuidadosamente estudada por Astudillo (2005). Por outro lado, segundo Moctezuma (s.d.), até 1850 não havia livros elementares de aritmética para crianças publicados no México. Posteriormente, surgiram o Catecismo de aritmética de José Urcullu, o Tratado elemental de aritmética de José Joaquín Terrazas, a Aritmética para los niños de Anselmo Camacho, os Elementos de aritmética de Tomas Mora, um frade franciscano, professor de aritmética e geometria em Bogotá, e o Tablas para los niños que empiezan a contar de Rafael Ximeno. ${ }^{10} \mathrm{O}$ fato de que o Tablas foi também publicado em Bogotá, um pouco após 1850, mostra, mais uma vez, que alguns dos livros de matemática usados na América espanhola eram conhecidos em mais de um país, o que pode ser confirmado pelas informações contidas em Alcaráz (2007) e Beyer (2015). Em geometria, foram utilizados os Elementos de Geometría de Faustino Paluzie, a geometría de Zamora e os professores se guiavam pelo Guía metodológica para la enseñanza de la geometría de Leopoldo Kiel (Moctezuma s.d.).

Segundo Moctezuma (s.d.), outros textos usados no México foram os Elementos de geometría de Faustino Paluzie, a Geometría de Zamora e os professores se baseavam no Guía metodológica para la enseñanza de la geometría, de Leopoldo Kiel. O Nociones de Geometría Práctica, do engenheiro Anselmo Camacho, professor do Instituto Científico y Literario del Estado de México, foi um dos livros mais populares usados no México no século XIX. Ainda segundo o mesmo autor, durante o Porfiriato, ${ }^{11}$ entre os livros de aritmética que foram utilizados no México, temos o Catecismo de aritmética de José Urcullu; o Tratado elemental de aritmética de José Joaquín Terrazas e a Aritmética para los niños, de Anselmo Camacho.

\footnotetext{
${ }^{10}$ Em Bogotá, 1857, Narciso González Lineros publicou os Elementos de Aritmética Del R.P. Fr. Tomas Mora puestos al nivel de las actuales necesidades de la enseñanza y del comercio. Em seu prefácio, menciona que o Manual de cuentas de Ximeno, também de 1857 tinha sido bem aceito. É conhecido um folheto com o mesmo nome, publicado em Monterrey, pela casa impressora de A. Zamorano, em 1836, embora seus autores possam ser A. Zamorano e José Mariano Romero. A Sociedade Zamorana, de Los Angeles, publicou, em 1976, o [Tablas para los niños que empiezan a contar.] The first school book printed in California with an exact facsimile reproduction of the unique copy in the Huntington Library. [Por José Mariano Romero] com uma introdução por Carey S. Bliss.

${ }^{11}$ O Porfiriato é o período de 30 anos, iniciado em 1876, durante o qual o general Porfirio Diaz governou, intermitentemente, o país.
} 


\section{Colômbia}

DOI: http://dx.doi.org/ 10.20396/zet.v25i2.8647053

A Colômbia criou sua academia militar, o Colegio Militar, em 1847, cujo objetivo era formar engenheiros civis e militares e seguia os modelos da École Polytechnique de Paris e da academia militar de West Point, nos Estados Unidos. Em seu currículo, a matemática era ensinada nos três primeiros anos (Sánchez, 2012, p. 115). Ainda segundo o mesmo autor,

[A] alma da academia foi Lino de Pombo (1797-1862), um engenheiro pertencente a uma das mais ilustres famílias da Nova Granada. Pombo estudou durante algum tempo na Universidad de Alcalá de Henares e concluiu seus estudos em Paris, na Écoles des Ponts et Chaussées (Sánchez 1999).

Lino de Pombo O'Donnell, nasceu em 1797, em Cartagena, na Colômbia, e morreu em Botogá, em 1862. Foi um político, diplomata, jornalista e militar que prestou relevantes serviços a seu país e o primeiro colombiano a receber o título de engenheiro civil. Teve participação ativa na vida política de seu país, e foi exilado na Espanha durante alguns anos.

Aimé Bergeron, ex-aluno da École Polytechnique, foi contratado para a cadeira de matemática. Ele foi extremamente importante por introduzir as modernas ideias matemáticas europeias na Colômbia (Albis-González and Sánchez 1999). O Colejio foi fechado em 1854 e reaberto em 1866, com o nome de Colegio Militar y Escuela Politécnica. No ano seguinte, a universidade nacional foi reorganizada e nela foi criada uma escola de engenharia, com os professores, alunos e currículo do Colejio (Sánchez, 2012, p. 116). Bergeron provavelmente ministrou o primeiro curso de cálculo infinitesimal na Colômbia, no Coléjio Militar.

Entre os livros usados no Colegio Militar podemos mencionar as Lecciones de Jeometría Analítica (1850), e as Lecciones de aritmética y áljebra (1858) de Lino de Pombo, e os Tratado de aritmética (1856) e Tratado de áljebra (1876) de Indalécio Liévano.

Indalécio Liévano Reyes (1834-1913), colombiano, foi matemático, engenheiro e astrônomo. Foi aluno de Bergeron e de Lino de Pombo, e tornou-se professor da Faculdade de Engenharia da Universidade Nacional da Colômbia e diretor do Observatório Astronômico Nacional. Seu Tratado elemental de aritmética (1856), certamente o mais importante trabalho matemático escrito durante o século XIX na Colômbia, contém a

[T]eoria dos incomensuráveis, a qual, embora não tão completa e perfeita como as de Weierstrass, Dedekind ou Cantor tem o mérito de ter sido publicada antes destas últimas (Sanchez, 2012, pp. 117-118).

Em 1871 ele publicou sua obra Investigaciones científicas, dividido em quatro partes: Teoría de las paralelas, Cuestiones de aritmética, Cuestiones de álgebra e Estudios filosóficos.

Embora tenha aumentado bastante nos últimos anos, ainda são fragmentários e esparsos os estudos sobre livros de matemática na América Latina. Uma exceção na América Espanhola é o projeto Grupo Proclo - Sistema de información de La producción matemática 
DOI: http://dx.doi.org/ 10.20396/zet.v25i2.8647053

colombiana, da Academia Colombiana de Ciências, ${ }^{12}$ que conseguiu identificar muitos dos livros de matemática usados na Colômbia, com seus autores ou tradutores e datas de publicação (Quadro 1). Uma adição valiosa a esses estudos, recente, é Beyer (2015), que estuda detalhadamente o caso da Venezuela.

Quadro 1 - Livros de matemática usados na Colômbia

\begin{tabular}{|c|c|c|c|}
\hline AUTOR & TÍTULO & $\begin{array}{c}\text { LOCAL DE } \\
\text { PUBLICAÇÃO }\end{array}$ & DATA \\
\hline D. H. Araújo & Tratado de álgebra & Cartagena & 1877 \\
\hline Simón Araújo & $\begin{array}{c}\text { Tratado de aritmética práctica, } \\
\text { segundo curso }\end{array}$ & Bogotá & $?$ \\
\hline Aimé Bergeron & $\begin{array}{c}\text { Lecciones de matemáticas. Parte } \\
\text { primera. Aritmética }\end{array}$ & Bogotá & 1848 \\
\hline J. M. Ch. & Compendio de álgebra & Tunja & 1893 \\
\hline N. González Lineros & Aritmética comercial razonada & Bogotá & 1857,1894 \\
\hline N. González Lineros & $\begin{array}{c}\text { Elementos de Aritmética del R. P. Fr. } \\
\text { Tomás Mora }\end{array}$ & Bogotá & 1863 \\
\hline Indalécio Liévano & Tratado de aritmética & Bogotá & 1856 \\
\hline Indalécio Liévano & Investigaciones científicas & Bogotá & 1871 \\
\hline Indalécio Liévano & Tratado de álgebra & Bogotá & 1875 \\
\hline Luis M. Lleras & $\begin{array}{c}\text { Elementos de Geometria, por A. } M . \\
\text { Legendre }\end{array}$ & Bogotá & 1866 \\
\hline Lino del Pombo & Lecciones de jeometría analítica & Bogotá & 1850 \\
\hline Lino del Pombo & Lecciones de aritmética y áljebra & Bogotá & 1858 \\
\hline Daniel Quijano, S. J. & Tratado de aritmética elemental & Bogotá & 1895 \\
\hline $\begin{array}{l}\text { Manuel Antonio Rueda } \\
\text { Jara }\end{array}$ & Lecciones de trigonometría & Bogotá & 1887,1926 \\
\hline $\begin{array}{l}\text { Manuel Antonio Rueda } \\
\text { Jara }\end{array}$ & Curso de álgebra & Bogotá & 1893,1926 \\
\hline $\begin{array}{l}\text { Manuel Antonio Rueda } \\
\text { Jara }\end{array}$ & $\begin{array}{c}\text { Las cuatro operaciones de la } \\
\text { aritmética }\end{array}$ & Bogotá & $?$ \\
\hline M. Antonio Suárez & Álgebra elemental & Ibagué/Bogotá & 1880,1883 \\
\hline $\begin{array}{c}\text { Temístocles \& Arístides } \\
\text { Paredes }\end{array}$ & Aritmética especulativa y comercial & Socorro & $1880\left(2^{a}\right.$ ed. $)$ \\
\hline
\end{tabular}

Fonte: Autor.

Cumpre assinalar que Rueda Jara (1858-1907) foi autor, além dos livros que constam do Quadro 1, das seguintes obras, muito usadas: Tratado de aritmética (1883), Aritmética analítica (1883), Compendio de aritmética (1884), Lecciones de álgebra (1887), Tratado de aritmética analítica y comercial (?), El juego de los números (?), e Contabilidad mercantil (?) (Sanchez, 1999, p. 703).

Arboleda (2002) mostra a grande influência, no período que investigamos, de livros franceses na Colômbia, no ensino superior

\footnotetext{
12 http://www.accefyn.org.co/proyecto/Libros/libros.htm.
} 


\section{Costa Rica}

DOI: http://dx.doi.org/ 10.20396/zet.v25i2.8647053

Não existem muitas informações sobre os livros texto de matemática usados em Costa Rica durante o século XIX. Ruíz (1995, p. 40) menciona os Elementos de geometría acompañados de algunos ejercicios practicos de Andres Girò y Aranols e I. R. Mirò (1862), o Aritmética para los niños e o Geometría para los niños, ambos de Acisclo Fernández Vallin y Bustillo, que viveu de 1835 a 1904. Era também usada a Aritmética primaria de Robinson e livros intitulados Aritmética comercial, escritos por um dos seguintes autores: González Lineros, Tejada ou Molina Rojo. Em geometria eram usados, menos frequentemente, os livros de Guim ou López Catalán. Além desses, eram também utilizados: Curso superior de aritmética y geometría de Vintéjoux; Tratado de aritmética (1846), Tratado de geometría elemental (1847) e o Tratado de trigonometría rectilinea y esférica y de topografia (1846), todos os três por J. Cortázar; Tablas de logaritmos vulgares desde el 1 hasta el 2000 (1855) de Vicente María Julián Vázquez Queipo de Llano (1804 - 1893) ${ }^{13}$ e os Éléments de géométrie descriptive; suivis de Notions de géométrie cotée (1882) de Jules Dufailly.

Ainda segundo Ruiz (1995), além desses livros, alguns outros eram recomendados como obras de referência, por exemplo, os Ejercicios prácticos de aritmética y geometría de Terry; Arithmétique de Leyssenne, os textos de aritmética de Lacroix, Ferry e Sánchez Vidal; os livros de geometria de Combette e de Rouché; o Cours de trigonometrie de Rebière e o Tratado de geometría descriptiva por Leroy. Ruíz menciona outro livro de geometria para a escola elementar, o Geometría objetiva para uso de las escuelas primarias por J. Dalsème, traduzido em Costa Rica (1888) por Austergildo Bejarano e Manuel Antonio Quirós. Em Costa Rica, como nos outros países da América Latina, eram necessários livros para ensinar o sistema métrico decimal. Entre eles temos o Sistema Métrico, demostrado según el aparato del método Level, traduzido por Manuel Antonio Quirós e publicado em 1886 (Ruíz 1995, p. 40).

\section{Chile}

No Chile, houve um grande incentivo para a tradução ou uso de livros de matemática europeus durante a curta permanência (1825-1826) do engenheiro francês Charles Ambroise Lozier no Instituto Nacional. ${ }^{14}$ Ele encomendou traduções de obras de Biot, Lacroix, Francoeur e encorajou os professores do Instituto a escrever seus próprios textos (Labarca, 1939, p. 82). Maldonado (1999, p. 27) afirma que Lozier tornou conhecidas no Chile várias obras importantes, entre elas o Traité de mécanique celeste de Laplace, a Mécanique analitique de Lagrange e fez traduzir, entre outros, o Dessin linéaire et arpentage e o Cours complet de mathématiques pures de Francoeur, traduzido como Curso completo de

\footnotetext{
${ }^{13}$ Queipo escreveu, também, Aritmética superior mercantil, de 1855.

${ }^{14}$ Charles Ambroise Lozier (1784-1864) foi um engenheiro francês que teve vida cheia de aventuras (veja Campbell, 1959, pp. 357-359 e Marcelin, 2001).
} 
DOI: http://dx.doi.org/ 10.20396/zet.v25i2.8647053

matemáticas puras, escrito en francês por L. B. Francoeur, traduzido al castellano de la $2^{a}$ edición y revista y aumentada consideravelmente por Andrés Antonio Gorbea, em 8 volumes. Gorbea também traduziu o Traité de géométrie descriptive de Leroy, com o título Tratado de geometria descriptiva, acompañado del método de los planos acotados e de La teoria de planos encargantes cilindros y cônicos, etc., publicado em Santiago, em 1845.

\section{Venezuela}

Tudo indica que o primeiro livro de matemática impresso na Venezuela foi Lecciones de aritmética, de Lucas María Romero y Serrano, publicado em 1826 por Tomás Antero, em Caracas (Beyer, 2006, p. 78). Dois anos depois, em 1828, foi publicada a Aritmética teóricopráctica de Ramón Aguilar, também em Caracas (Beyer, 2006, p. 81). A partir de 1830, o processo de desmembramento da Grande Colômbia interrompeu quase que totalmente a produção de livros texto. Malgrado isso, foram publicadas, em 1831, as Lecciones de aritmética razonada (...) para la enseñanza de los niños, de Domingo Navas Spínola (Beyer, 2006, p. 85). Um pouco mais tarde, em 1839, foi publicada a primeira edição, na Venezuela, da tradução da aritmética de Lacroix por Rebollo y Morales (Beyer, 2006, p. 90). Em seguida, devemos mencionar (Beyer, 2006, p. 96) um livreto publicado em 1840, Conocimientos de las definiciones de las tablas de sumar, restar, multiplicar y partir, de autor desconhecido e o Compendio de aritmética razonada, segundo Lacroix, por Martín Chiquito (1842). Também em 1842 foi publicada a mesma obra com título Aritmética razonada, según Lacroix. Seguem-se o Compendio de aritmética razonada, de Manuel María Echeandía, publicado em 1843, com muitas edições e os Elementos de aritmética teórica y práctica por Juan Bautista Montenegro, de 1844, também com muitas edições; O Compendio de aritmética teórica y práctica de Alejandro Ibarra, em dois volumes, publicados respectivamente em 1855 e 1860 . A aritmética de Lacroix foi mais uma vez traduzida para o espanhol e publicada em Caracas, por autor desconhecido, que adicionou uma introdução e um apêndice à obra. O livro não traz indicação da edição francesa usada e há informações conflitantes quanto a sua data de publicação, 1862 e 1865. Em 1895 foi publicado, em Caracas, o Tratado de aritmética esencialmente práctica y nociones sobre sistema métrico decimal, por Marcos V. Landáez. Sabemos também que os Elementos de geometría, de Legendre, a Álgebra traducida al castellano de Lacroix, o Compendio de aritmética de Montes Ramón e o Compendio de aritmética para uso de los alunos que asisten a las escuelas primarias de Venezuela, de 1867, por Eduardo Ochoa foram usados na Venezuela antes de 1872 (Beyer, 2006, p. 101). Encontra-se, em Beyer (2015), uma visão bem mais completa e estruturada dos livros de matemática usados na Venezuela.

\section{Catecismos de matemática}

Um fato interessante sobre a educação matemática na América Espanhola foram os catecismos de matemática, escritos por liberais espanhóis que se auto-exilaram em Londres, ${ }^{15}$

15 A partir de 1823, com a invasão Francesa para restaurar o Antigo Regime, com Fernando VII.

Zetetiké, Campinas, SP, v.25, n.2, maio/ago.2017, p.240-253.

ISSN 2176-1744 
DOI: http://dx.doi.org/ 10.20396/zet.v25i2.8647053

para uso nos novos países da América espanhola, nos quais havia grande falta de textos para a escola elementar (Ausejo \& Hormigón, 1999; Beyer, 2009). Estes catecismos ensinavam matemática na forma de perguntas e respostas, como os catecismos religiosos muito usados no século XIX e eram particularmente apropriados para o uso com o método de instrução mútua de Lancaster, que foi muito usado na América Latina, nas primeiras décadas do século XIX (Beyer, 2015; Carvalho, 2015). Os dois principais autores desses catecismos foram José de Urcullu e José Núñez de Arenas, que se basearam nos Princípios de matemática de Bails. Beyer (2009) descreve 22 catecismos de matemática, nove deles publicados entre 1825 e 1849, alguns dos quais tiveram vidas surpreendentemente longas. Por exemplo, o Compendio de aritmética razonada estractado de los mejores autores, para el uso de los jovenes que asisten à los colegíos y a las escuelas de primeras letras, de Manuel Maria Echeandia, ainda era publicado em 1926, 82 anos após sua primeira edição. Beyer também menciona, em outro trabalho, a famosa Aritmética de Juan José de Padilla, publicada em 1732, na Guatemala (Beyer 2006, p. 80). Até agora, só localizamos um catecismo de matemática no Brasil no século XIX, escrito por Daniel Pedro Muller que publicou, além de catecismos de vários outros assuntos, o Cathecismo de arithmetica, no Rio de Janeiro, em data desconhecida (Blake, 1893, p. 160) ${ }^{16}$.

\section{Considerações finais}

Os livros que constam desse levantamento mostram duas grandes influências: da Espanha e da França. Enquanto a primeira se faz notar em todos os níveis de escolaridade, a segunda se dá, sobretudo, no ensino secundário e pós-secundário. A existência de bons textos de matemática espanhóis e a herança cultural que as antigas colônias espanholas receberam da antiga metrópole garantiram não só um papel importante dos livros de matemática espanhóis no Novo Mundo. Isso explica também porque alguns desses textos foram usados em vários dos países da América Espanhola. Um exemplo bem estudado da influência francesa se encontra em (Arboleda 2002), para a Colômbia. À medida que o século XIX avança, surgem mais e mais livros de autores latino-americanos, principalmente para os ensinos primário e secundário, que se estruturam ao longo do século (Carvalho, 2014) e a influência francesa e espanhola se nota principalmente nos cursos pós-secundários. No Brasil, diferentemente, praticamente não se nota influência portuguesa, somente francesa.

Outro fato que se observa é o surgimento da profissão de autor de livros de matemática, à medida que o século XIX avança e no século XX, entre outros Manuel Antonio Rueda Jara, na Colômbia. ${ }^{17}$ Isso foi possível devido à institucionalização e ampliação crescente dos sistemas de ensino das várias repúblicas latino-americanas, o que tornou possível a profissionalização da atividade editorial de livros de matemática (elaboração, produção, distribuição).

\footnotetext{
${ }^{16}$ Comunicação pessoal de Bruno Alves Dassie.

${ }^{17} \mathrm{O}$ caso do Brasil foi analisado em Soares (2011).
} 


\section{Referências}

DOI: http://dx.doi.org/ 10.20396/zet.v25i2.8647053

Alcaráz, M. G. G. (2007). Libros de texto para la ensenanza de las matemáticas en México, 1890-1920. Actas del IX Congreso Nacional de Inverstigación Educativa. Mérida, México.

Albis-González, V. S., \& Sánchez, C. H. (1999). Descripción del curso de cálculo diferencial de Aimé Bergeron en el Colejio Militar. Revista de la Academia Colombiana de Ciencias Exactas, Fisicas y Naturales (23), 73-79.

Arboleda, Luis Carlos. (2002). Los tratados franceses en la enseñanza del análisis en Colombia (1851-1951): Sturm, Humbert y los otros. Revista de la Academia Colombiana de Ciencias Exactas, Físicas y Naturales, (26), 533-543.

Astudillo, M. T. G. (2005). El Compendio de matemáticas de José Mariano Vallejo. Actas del IX SIMPOSIO SEIEM. Córdoba, Argentina.

Ausejo, E., \& Hormigón, M. (1999). Mathematics for independence: From Spanish liberal exile to the young American republics. Historia mathematica, (26), 314-326.

Beyer, W. O. (2006). Algunos libros de aritmética usados en Venezuela en el período 18261912. Revista de Pedagogia, Caracas, 27(78), 71-110.

Beyer, W. O. (2009). Catecismos y matemáticas: confluencia de corrientes de pensamiento. Paradígma [online], 30(1), 117-150. [Retirado em 14 de outubro de 2012].

Beyer, W. O. (2015). Um paseo histórico por La educación matemática venezolana: uma visión a través de lós textos escolares. In M. Chaquiam, I. A. Mendes \& W. R. Valente (orgs). Anais do III Congresso Ibero-Americano de História da Educação Matemática. Belém, PA.

Blake, A. V. A. S. (1893, 1969). Diccionario Bibliographico Brazileiro, (vol. 2). Rio de Janeiro. Liechttenstein: Kraus Reprint.

Burdick, B. S. (2009). Mathematical works printed in the Americas, 1554-1700. Baltimore, MD: The Johns Hopkins University Press.

Campbell, M. V. (1959). Education in Chile, 1810-1840. Journal of Inter-American studies, $1(3), 353-375$.

Carvalho, J. B. P. F. (2015). From Lancaster to Pestalozzi - changing views of mathematics education in Latin Americda during the nineteenth century. In K. Bjarnadottir,F. Furinghetti, J. Prytz, \& G. Schubring (Eds.) Proceedings of the III international congress on the history of mathematics education. Uppsala: Uppsala Universitet.

Carvalho, J. B. P. F. (2014). Mathematics education in Latin America. In Karp, A. \& Schubring, G. (Eds.) Handbook on the history of mathematics education. New York: Springer, 335-360.

Frieiro, E. (1957). O diabo na livraria do cônego. Belo Horizonte, MG: Itatiaia. 
DOI: http://dx.doi.org/ 10.20396/zet.v25i2.8647053

Garcia, V. A. L. (1998). História de los inicios de la enseñanza del cálculo infinitesimal en México. Revista Latinoamericana de investigación en matemática educativa, 1(2), 2950.

Garma Pons, S. (1973). Las matematicas en España en los principios del siglo XIX. Revista de Occidente, (118), 105-114.

Gentil Baldrich, J. M. (1999). Nuevos datos sobre la vida y la obra de José Mariano Vallejo y Ortega. Llull, 22(44), 381-404.

Hallewell, L. (1982). Books in Brazil: a history of the publishing trade. N. J. Metuchen: The Scarecrow Press.

Hallewell, L. (2005). O livro no Brasil. São Paulo, SP: EdUSP..

Labarca, A. (1939). História de la enseñanza en Chile. Santiago: Imprenta Universitária.

Maldonado, J. P. C. (1999). La influencia cultural francesa en la educación chilena, 1840-. Santiago, Chile: Ediciones Universidad Católica Cardenal Raúl Silva Henríquez (Serie Investigación, 17).

Marcelin, J. (2001). Là où finit la terre: Lozier, un Français au Chili. Paris: Éditions des écrivains.

Martínez, M. M. (s/d). Ilustración y reforma. La biblioteca de Francisco de Saavedra, segundo indendente de Caracas. Retirado em 12 de junho de 2015 de: http://dspace.uah.es/dspace/bitstream/handle/10017/5783/Ilustraci\%C3\%B3n\%20y\%20R eforma.\%20La\%20Biblioteca\%20de\%20Francisco\%20de\%20Saavedra, $\% 20$ Segundo $\% 2$ 0Intendente $\% 20 \mathrm{de} \% 20$ Caracas.pdf?sequence $=1$.

Moctezuma, L. M. (s/d). Los libros de texto en el tiempo. Retirado em 12 de junho de 2012 de: http://biblioweb.tic.unam.mx/diccionario/htm/articulos/sec_29.htm.

Palacio, P. N. (1983). Estudo critico de Benito Bails, De la arquitectura civil, tomo primero. Múrcia: Colegio oficial de aparejadores y arquitectos técnicos de Múrcia.

Perez, C. H., \& Sánchez, J. M. (1990). José Mariano Vallejo: notas para uma biografia científica. Llull, (13), 427-446.

Ruíz, A. (1995). Historia de las matemáticas en Costa Rica. Una introducción. San José, Costa Rica: Editorial de la Universidade de Costa Rica.

Sánchez, C. H. (1999). Matemáticas en Colombia en el siglo XIX. LLull, (22), 687-705.

Sánchez, C. H., \& Albis, V. (2012). Historia de La enseñanza de las matemáticas en Colombia: De Mutis al siglo XXI. Quipu 14(1), 109-157.

Schubring, G. (2003). Análise histórica de livros de matemática. Campinas, SP: Autores associados.

Silva, C. M. S.. (2009). O livro didático mais popular de Leonhard Euler e sua repercussão no Brasil. Revista Brasileira de História da Matemática (RBHMAT), 9(17), 33-52. 
DOI: http://dx.doi.org/ 10.20396/zet.v25i2.8647053

Silva, M. B. N. (1981). Cultura no Brasil colônia. Petrópolis, RJ: Vozes.

Smith, D. E. (1921). The sumário compendioso of brother Juan Diez. Boston: Ginn and Company.

Soares, F. S. (2011). Professores-autores de compêndios de matemática no século XIX. Anais do XII CIAEM-IACM. Recife, Brasil.

Soubeyroux, J. (1995). El real seminario de nobles de Madrid y la formacion de las élites en el siglo XVIII. Bulletin Hispanique, 97(1), 201-212.

Valente, W. R. (2008). Livro didático e educação matemática: uma história inseparável. Zetetiké, 16(30), 139-162. 